\title{
BIO OPTICAL MODELLING OF LAGUNA LAKE USING BOMBER TOOL AND WASI-DERIVED INVERTED PARAMETERS
}

\author{
R. L. Jalbuena ${ }^{1,2}$, A. C. Blanco ${ }^{1,2}$, A. Manuel ${ }^{1,2}$, R. R. Sta. Ana ${ }^{2}$ J. A. Santos ${ }^{2}$ \\ ${ }^{1}$ Department of Geodetic Engineering, University of the Philippines, Diliman, Quezon City, Philippines - (rljalbuena, \\ acblanco)@up.edu.ph, amimanuel@gmail.com \\ ${ }^{2}$ Training Center for Applied Geodesy and Photogrammetry, University of the Philippines, Diliman, Quezon City, Philippines - \\ (raasdafsa, jacessantos)@gmail.com
}

KEY WORDS: Water Quality, Bio-optical Modelling, Inverse Modelling, Spectroscopy, Water quality mapping, Water quality Modelling

\begin{abstract}
:
Laguna Lake is significant to its surrounding cities and municipalities as it serves multiple purposes: flood basin, aquaculture, water source for irrigation and domestic use, among others. Monitoring the lake's water quality is an integral part ensuring that the lake would continue to serve its purposes. Bio-optical modelling is a type of empirical model that relates the inherent optical properties of water to different biological properties like chlorophyll-a. The BOMBER (Bio-Optical Model Based tool for Estimating water quality and bottom properties from Remote sensing images) tool makes use of the different IOPs apparent optical properties (AOPs) of satellite images to be able to produce water quality maps. To localize the parameters used by the BOMBER tool, the use of WASI (The Water Color Simulator) tool was introduced. Inverting in situ spectral measurements of the lake, WASI tool was able to produce parameters localized for the lake. This research used 2018 Landsat 8 Images to produce images and used a water profiler to validate results. Results show the bio-optical model provided a R-squared value of 0.6912 and an RMSE of $2.43 \mu \mathrm{g} / \mathrm{l}$ which shows good correlation between the in-situ and the bio-optical model results.
\end{abstract}

\subsection{Bio-Optical Modelling}

\section{INTRODUCTION}

One of the main applications of remote sensing is the water quality estimation of water bodies. Using remote sensing for water quality mapping is advantageous because of the abundance of data, and the large scale of the area an image can have. One of the approaches for estimating water quality is biooptical modelling. The concept of bio-optical modelling came from the expression "bio-optical state of ocean waters" in 1978 (Ogashawara, Mishra, \& Gitelson, 2017). A bio-optical model is a tool used to analyse and predict the optical properties and biological materials in bodies of water. Models are created to address the need to acknowledge that optical properties of water bodies are essentially subordinated to its biological activity and are significant in determining the current and possible sate of a water body.

There are two major classification of bio-optical models, the empirical models and analytical models (Gege, 2017). The Empirical models derive information about the biological and physical processes in the water body by establishing relationships between the radiometric measurements and optically active constituents. On the other hand, analytical models derive the composition of the constituents of the water through a ratio of their absorption coefficients and specific absorption coefficients, and backscattering coefficients.

One of the challenges that bio-optical modelling currently facing is the validity of the model to local body of water. As most of the models are created for a specific lake, bay, river, or sea. There is a need for a way to have its parameters and input values localized to the study area that is going to be studies

\subsection{Spectroscopy and Water Quality}

One of the fundamental parameters for coastal and inland water quality mapping using remote sensing is spectral reflectance, a ratio of the light reflected from a target and to that incident on it at every wavelength (Giardino, Bresciani, \& Braga, 2017). Each material on the Earth's surface has its own reflectance, absorptance and transmittance properties that are used in discriminating them from other objects. The amount of energy that is reflected (or emitted) from the object depends on the material, surface roughness, intensity and wavelength of radiant energy. This unique response to the electromagnetic spectrum is the spectral signature. Field spectroscopy is the measurement of the interactions between the solar electromagnetic radiation (EMR) and objects in its natural environment (Jiménez, González, Amaro, \& Fernández-renau, 2015).

Water spectral signatures holds key information with regards to the inherent optical properties (IOPs) of the optically active constituents of the concentrations of water quality parameters such as phytoplankton, suspended matter and coloured dissolved organic matter (CDOM).

\section{Study Area}

Laguna Lake $\left(14^{\circ} 11^{\prime}-14^{\circ} 33^{\prime} \mathrm{N}, 121^{\circ} 03^{\prime}-121^{\circ} 29^{\prime}\right.$ E) is bounded by the province of Laguna in the east, west, and southwest, the province of Rizal in the north to northeast, and Metro Manila in the northwest (Figure 1). Considered as the largest lake (approximately $900 \mathrm{~km}^{2}$ ) in the Philippines, Laguna Lake is divided into four main bays, namely, East, West, South, and Central. The lake is a multi-use lake, supporting the aquaculture industry, providing water supply, and enabling transportation of people and good between communities, among others. Aquaculture activities are primarily pervasive in the West Bay and Central Bay. 
Climatically, Laguna Lake experiences dry and wet seasons and indeed, its water quality varies accordingly. During the dry season (December to May), the lake level falls below the level of high tide in Manila Bay that results to intrusion of seawater to Pasig River which is the sole outlet of the lake. At this time of the year, the water turns out to be more saline due to the highly polluted waters of Pasig River being discharged into the lake. Moreover, the increased salinity by then that is caused by tidal influx or fluctuation is what makes the waters of the lake naturally brackish. On the other hand, waters are observed to be more turbid during wet season, especially after typhoons or heavy rainfall. The lake's shallow average depth of 2.5 meters accounts for its turbid characteristic. Turbidity can even more severe by wind action due to suspension of lake bottom sediments. Laguna Lake reaches its maximum level between September and November (wet season), and then falls by an average of 1.7 meters to its lowest level in May or June. (Herrera, Nadaoka, Blanco, \& Hernandez, n.d.)

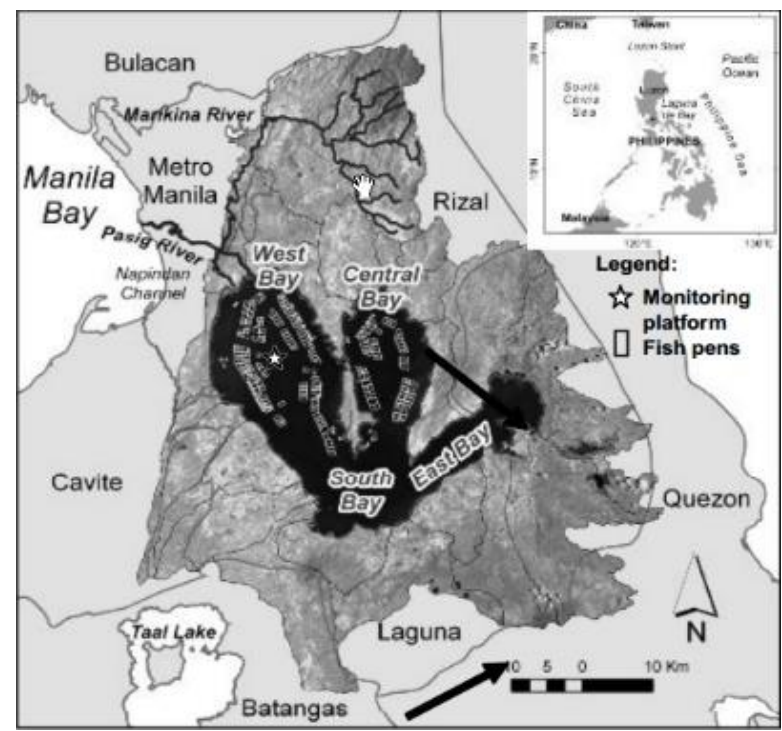

Figure 1. Laguna Lake and surrounding watershed which spans across Metro Manila and four provinces.

The study aims to produce water quality maps using a biooptical model with parameters localized to the lake. The results could provide important information about the behaviour of the lake and could be further on be used by agencies that manages and oversights the lake.

\section{METHODOLOGY}

The methodology is divided into a few sub parts (Figure 2). First is the Pre-processing of the image which includes the radiometric calibration, atmospheric correction, cloud masking, land masking, image sub setting, and the image rescaling of the data. These are conducted to prepare the data for bio-optical modelling. The next part is the inversion of the in-situ field spectra using the Water Color Simulator (WASI) software. The inversed spectral parameters (e.g., absorption and backscattering coefficient) which will serve as inputs in the biooptical model. Third part of the methodology is the implementation of the bio-optical Model using the Bio-Optical Model Based tool for Estimating water quality and bottom properties from Remote sensing images (BOMBER) tool. Lastly, the bio-optical modelling results are compared with in situ water quality measurements.

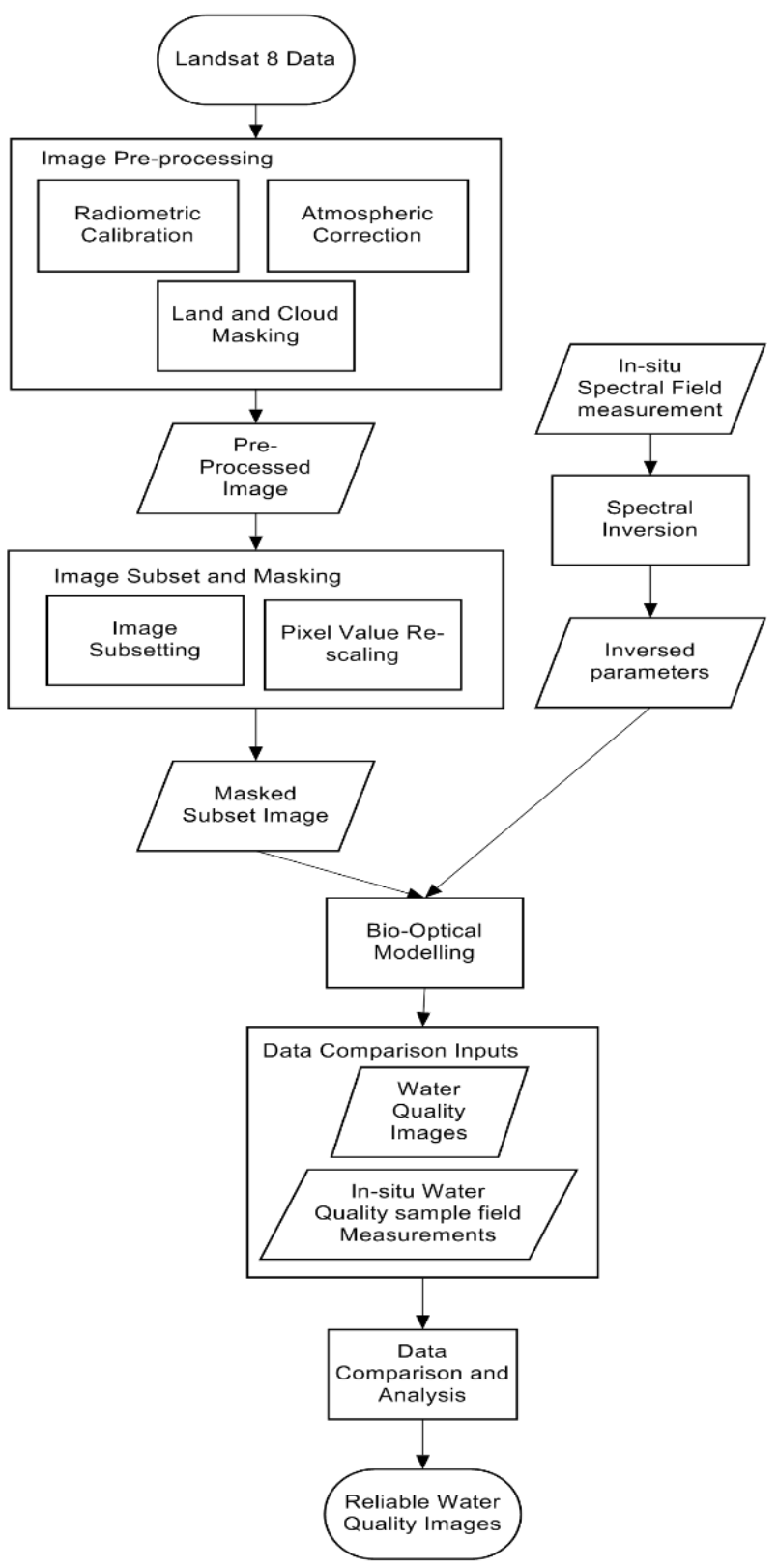

Figure 2. Methodology for water quality mapping using biooptical modelling

\subsection{Image pre-processing}

\subsubsection{Data Used}

Landsat 8 was used for this study. Image from October 16, 2018 was used as it was the day that all the field measurement (spectral and water quality) were done. Landsat 8 is a $30 \times 30$ meter resolution image with 9 bands. Though for this study only the seven multi spectral bands, namely, Coastal band $(0.443$ $\mu \mathrm{m})$, Blue band $(0.483 \mu \mathrm{m})$, Green band $(0.563 \mu \mathrm{m})$, Red band $(655 \mu \mathrm{m})$, Near Infrared band $(0.865 \mu \mathrm{m})$, Short Wavelength infrared band $1(1.610 \mu \mathrm{m})$, and Short wavelength infrared band $2(2.200 \mu \mathrm{m})$ are used.

Figure 3. shows the coverage of the Study area taken form a Landsat 8 image. 


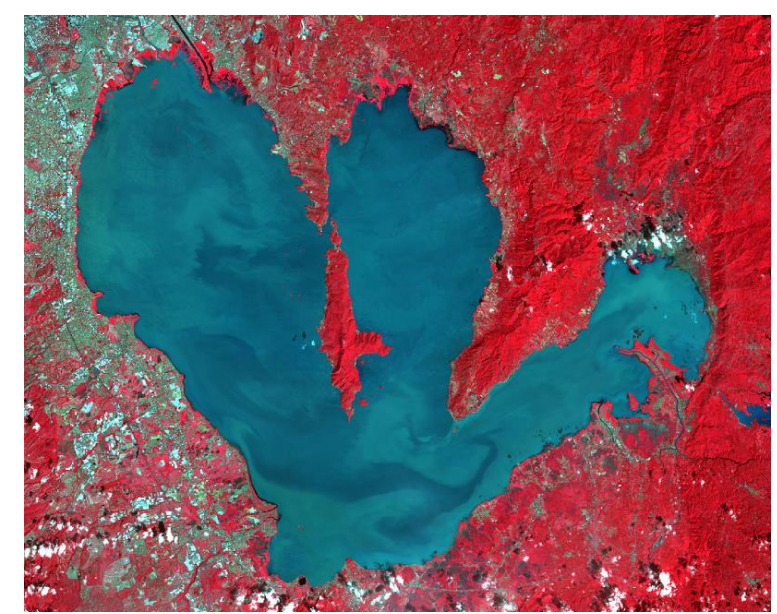

Figure 3. Landsat 8 image in false color covering Laguna Lake acquired on Feb 16, 2016

\subsubsection{Cloud and Cloud Shadow Masking}

Tmask model (Zortea, Salberg, \& Trier, 2012) was used for the cloud masking of the image. The main idea is to remove most clouds using the initial masks. After the initial masks, the multitemporal information became the inputs for the model defining the behaviour of values for each pixel during cloud-free situations for any day. With this model, the pixel value for clear observations can be predicted in a way. This model or predicted values became the threshold that if a pixel value deviates a certain value from the model, then it is not considered as a clear pixel. It can be considered as cloud or snow. Since the study area is in the tropical region where there is no snow, we disregard anything that relates to snow in the model

A time series model of sines and cosines is used to estimate the model values. The equation of the model is shown below.

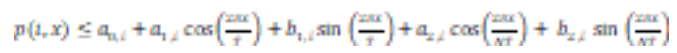

Where:

$$
\begin{aligned}
& \mathrm{X}=\text { Julian date } \\
& \mathrm{I}=\text { Landsat Band } \mathrm{I} \text { TOA reflectance } \\
& \mathrm{T}=\text { number of days per year }(\mathrm{T}=365)
\end{aligned}
$$

$\mathrm{N}=$ number of years (round to the nearest integer greater than or equal to $\mathrm{N}$ )

$$
a, b=\text { coefficients }
$$

\subsubsection{Radiometric Calibration and Atmospheric Correction}

Radiometric Calibration is performed to convert the digital number $(\mathrm{DN})$ values to radiance or brightness values. After applying the radiometric correction, the pixel values in the image represent the at-sensor radiance values. The radiance file produced are processed further to obtain the reflectance values of the ground features using atmospheric correction.

Atmospheric correction removes the effects of the atmosphere, thus giving the surface reflectance values of the ground features, including water. For this research, the Fast Line-of-sight Atmospheric Analysis of Hypercubes (FLAASH) was used .

$$
L=\left(\frac{A \rho}{1-\rho_{p} s}\right)+\left(\frac{B \rho_{p}}{1-p_{p} s}\right)+L_{L}
$$

$\rho e=$ average surface reflectance for the pixel and a surrounding region

$\mathrm{S}=$ spherical albedo of the atmosphere

$\mathrm{La}=$ radiance back scattered by the atmosphere

$\mathrm{A}$ and $\mathrm{B}=$ coefficients that depend on atmospheric and geometric conditions but not on the surface

\subsubsection{Image Subset and Re-scaling}

To decrease image processing time, the data set must be subset to the area of interest which is the Laguna lake. This was done through region of interest tool in the ENVI software.

Image Pixel Rescaling is performed so that the scale of the pixel spectral value will match the scale that is used by the Bomber tool. The image was rescaled using the band math tool of ENVI. All of the seven bands of the image will have its pixel values divided to 100,000 . After which, each band is stacked again to produce a single image file. This was done as it is the spectral profile that is input to the bio-optical model.

\subsubsection{Land Mask}

Land mask is essential to the methodology as the bio-optical model tool that is used processes all the pixels in the image. To decrease further the processing time a land mask was used to cover pixels of land which are not areas of concern in the image. The Land mask was created through the use of a Normalized Difference Water Index (NDWI) To create an NDWI, the NIR (Near Infrared) band and the SWIR (Short Wave Infrared) band is needed.

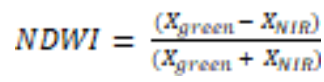

Where:

$$
\begin{aligned}
& X_{\text {green }}=\text { Green }(\text { Band } 3 \text { Landsat } 8) \\
& \left.X_{\text {NIR }}=\text { Near Infrared band (Band } 5 \text { Landsat } 8\right)
\end{aligned}
$$

The resulting NDWI band will have its water pixels to have values from $0-1$. While the land area will have negatives or more than one value. After which the create mask tool is used. The resulting image (Figure 4.) will show areas of the Laguna Lake with no land and cloud pixels.

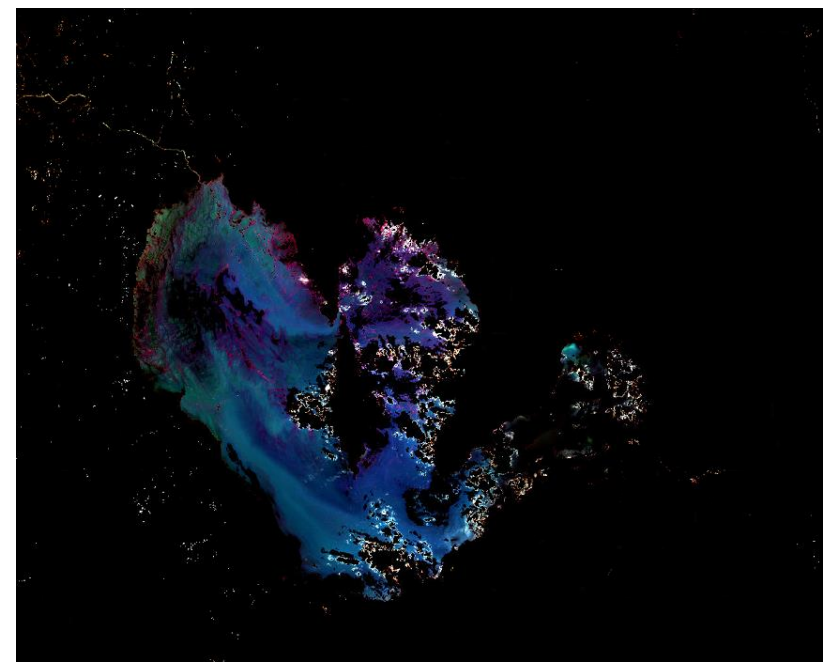

Figure 4. Laguna Lake cloud and land masked image

Where: $\quad \rho=$ pixel surface reflectance 


\subsection{In-situ spectral and water quality measurement}

Spectral signatures were collected during the overpass of the image (October 16, 2018). They were collected through field spectrometer Ocean Optics USB2000+ VIS-NIR. (Figure 5) shows an example of a field spectra collected in the field.

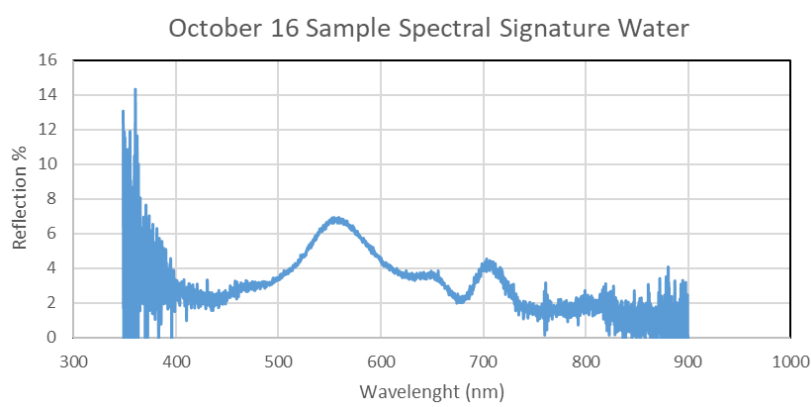

Figure 5. Sample Field Spectra for Oct 16, 2019

For water quality in situ measurements, a continuously data logging turbidity-chl-a sensor was deployed and towed along the boat track 1 (Figure 6). The sensor logged data every second for the whole duration of the field survey. Chlorophyll-a values obtained ranged from 3-20 $\mu \mathrm{g} / \mathrm{l}$. As seen in (Figure 6) the values of the chl-a differ throughout the lake. Areas in red (east part of the central bay) have higher values of chl-a compared to the green and yellow aras (rest of the area)

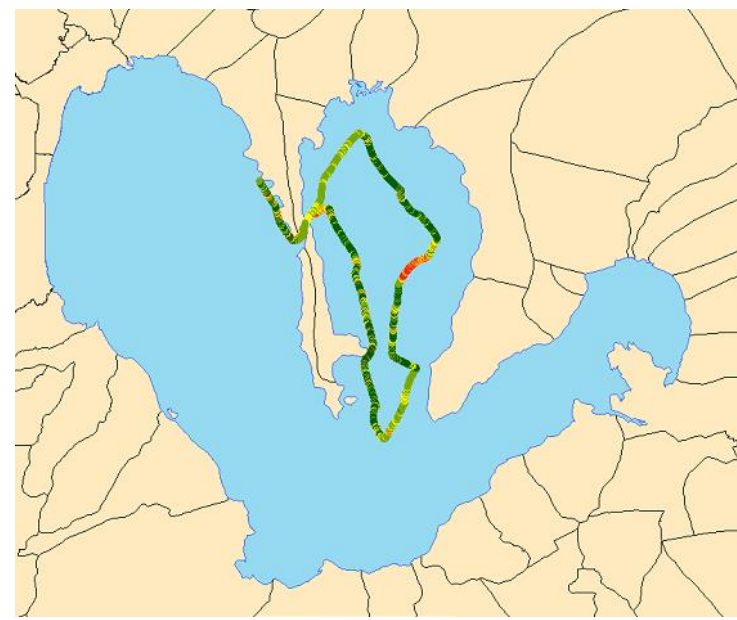

Figure 6. Field GPS tract with CLW data for Oct 16, 2018

\subsection{Spectral Inversion using WASI}

The BOMBER tool requires a lot of parameter inputs. Most of them have initial value based on the lake studied by (Giardino et al., 2012). In order to localize and fully optimize the tool, the parameter values must be determined according to the properties of the local study area. This can be done with the spectral inversion of sample spectral signatures of Laguna Lake waters. The results then serve as inputs for the BOMBER tool.

Before proceeding with the inversion process with WASI (Gege, 2014), a spectral smoothing feature is done if the field spectra acquired is noisy (Figure 8). For this process, the Savitzky-Golay smoothing filter (Kim, Jeung, \& Kim, n.d.) was applied using a python script.

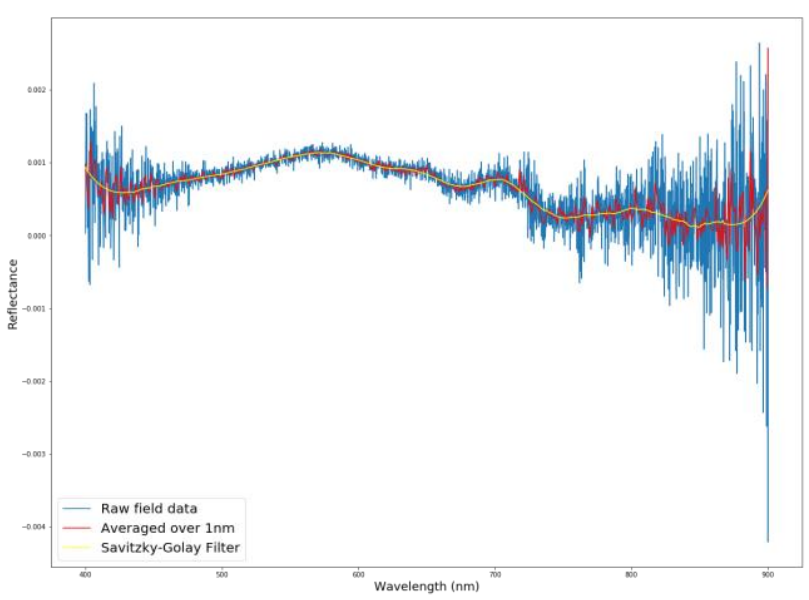

Figure 7. Sample spectral data smoothing using Savitzky-Golay filter

Once inputted into the WASI software, the first few runs were done with the fit parameters as constant.

An initial WASI run gave values and results and do not necessarily match the field acquired values for chlorophyll. This is due to one spectral shape not necessarily corresponding to a unique set of water quality parameters for the same sun illumination patterns. Therefore, incorporation of a constant value or setting of initial parameters was tested out to improve model performance. In situ chl-a measurements was used as a constant to help guide the inversion model that this is the baseline or field acquired value, so it would set the initial simulated spectra closer to the actual field value.

WASI generated different IOP spectra including the absorption and backscattering spectra, which are needed in the subsequent bio-optical modelling.

\subsection{Bio-optical Modelling using BOMBER tool}

The BOMBER tool is a software package for the simultaneous retrieval of the optical properties of water column and bottom from remotely sensed imagery, which makes use of bio-optical models for optically deep and optically shallow waters. Several menus allow the user to choose the model type, to specify the input and output files, and to set all the variables involved in the model parameterization and inversion. The optimization technique allows the user to retrieve the maps of CHL-A concentration, suspended particulate matter (SPM) concentration, and CDOM.

The bio-optical model implemented in the BOMBER tool is based on the works of (Albert \& Mobley, 2003) and (Carder, Steward, Lee, Mobley, \& Patch, 2008; Lee, Carder, Mobley, Steward, \& Patch, 1999) The above remote sensing reflectance is expressed as a function of the radiance reflectance from the approximated sum of the contributions from the water column and the bottom

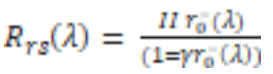

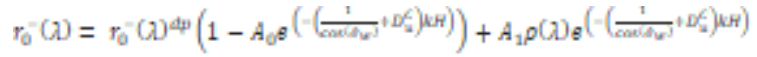

$$
\begin{aligned}
& P_{0}(\lambda)=\left(g_{n}+g_{1} u(\lambda) g_{2}\right) u(\lambda) \\
& u(\lambda)=\frac{a(\lambda)}{a(\lambda)+b_{b}(\lambda)}
\end{aligned}
$$


II and $\gamma$ (Eq.4) are model parameters which take into account the effects of air-water interface on the transmission of radiance. The $r_{0}^{-}(\lambda)^{4 p}$ (Eqs 2 and 3) are the contribution of deep waters in $\operatorname{sr}^{-1}$. The $\cos \left(v_{w}\right)$ and $\mathrm{H}$ (Eq. 2) are the cosine of the underwater sun zenith angle and the bottom depth respectively. While $u(\lambda)$ (Eq. 4) is a function of two IOPs: total absorption coefficient $a(\lambda)$ and the total backscattering coefficient $b_{b}(\lambda)$. Lastly g0, g1, g2, A0, $\mathrm{D}_{\mathrm{u}}{ }^{\mathrm{C}}, \mathrm{D}_{\mathrm{u}}{ }^{\mathrm{B}}$ and $\mathrm{k}$ are biooptical model parameters which are described in detail in (Lee, et al., 1999)

The BOMBER tool makes use of several inputs for it to fully operate. It uses absorption and backscattering coefficients of the water body which, in this research, are the inversed spectra obtained from WASI. BOMBER also uses calibration parameters whose default values are taken from (Lee et al., 1999). Starting values are also optimized since the technique is a trial and error procedure. It is done by indicating values that are historical average of the water quality parameters. In this research, the following values based on historical data were used: $5 \mu \mathrm{g} / \mathrm{l}$ for CHL-A, $40 \mu \mathrm{g} / \mathrm{l}$ for SPM, and $10\left(\mathrm{~m}^{-1}\right)$ for CDOM.

\section{RESULTS}

\subsection{Discussion}

The estimated CHL-A (Figure 8) ranged from 0 to $30 \mu \mathrm{g} / \mathrm{l}$ but most of the values are within 5-20 $\mu \mathrm{g} / \mathrm{l}$. For SPM (Figure 9), the result ranges from $0-90 \mu \mathrm{g} / \mathrm{l}$ with bulk of the values concentrating in the $30-60 \mu \mathrm{g} / \mathrm{l}$ range. The CDOM (Figure 10) range is lower at $0-17 \mathrm{~m}^{-1}$.

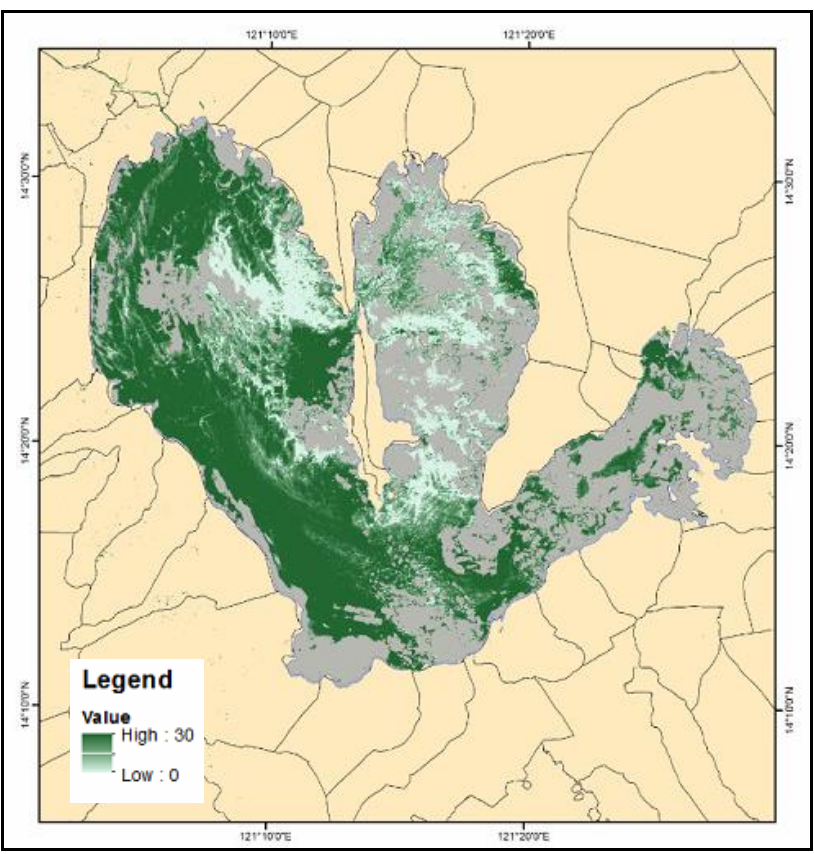

Figure 8. BOMBER tool derived CHL-A Map of Oct 16, 2018

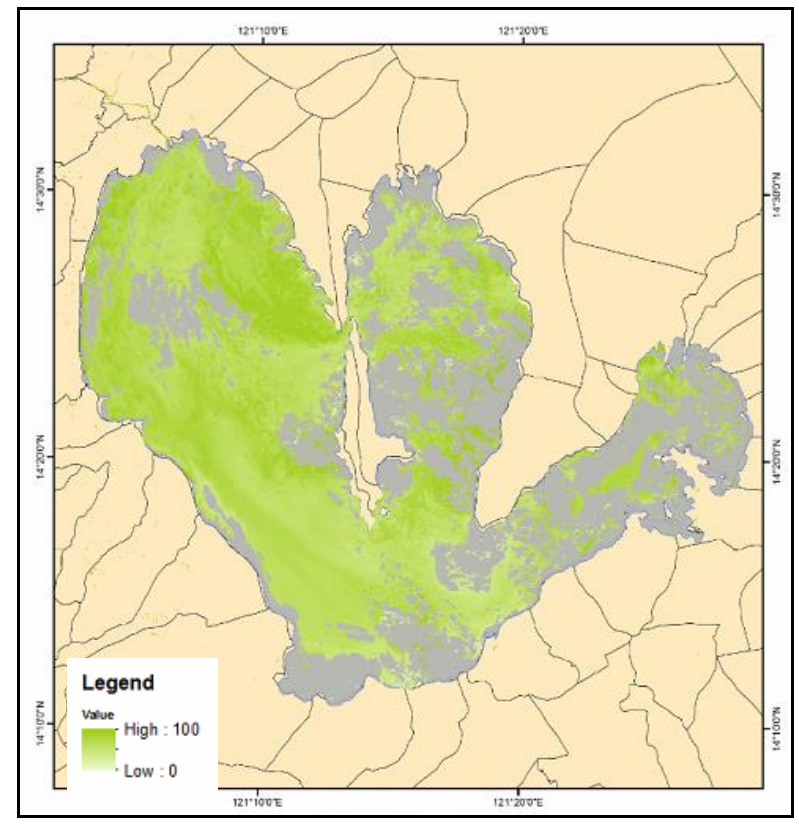

Figure 9. BOMBER tool derived CDOM Map of Oct 16, 2018

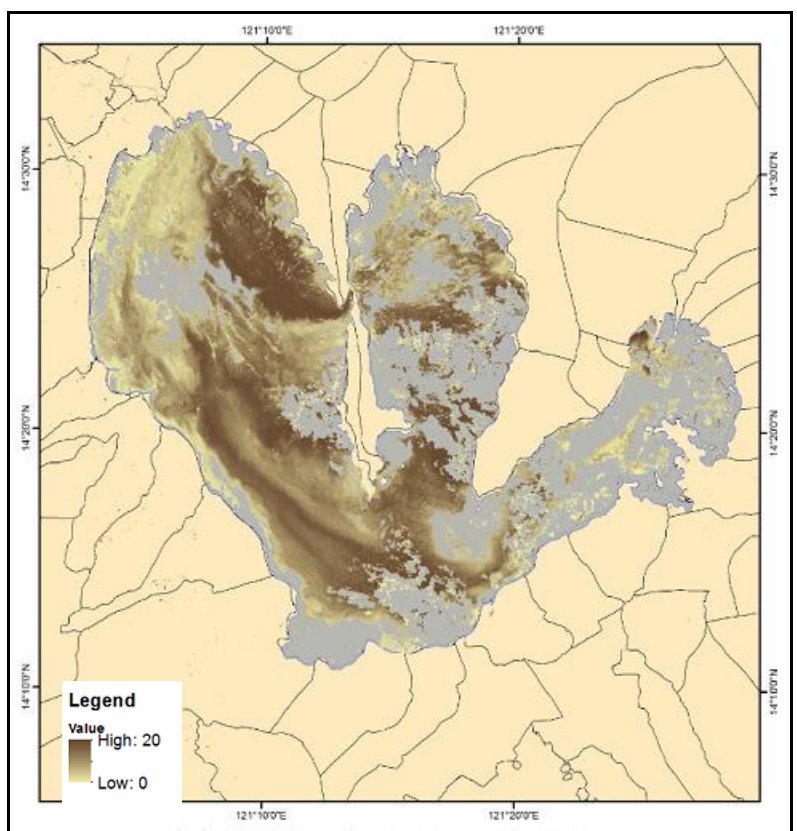

Figure 10. BOMBER tool derived SPM Map of Oct 16, 2018

\subsubsection{Comparison with in situ field measurements}

The pixel values of the resulting CHL-A layers from BOMBER were compared with the in situ chl-a measurements. Considering the spatial resolution $(30 \mathrm{~m})$ of Landsat 8 image, values at field points within each pixel were averaged to obtain the representative value. Outlier values were excluded. 


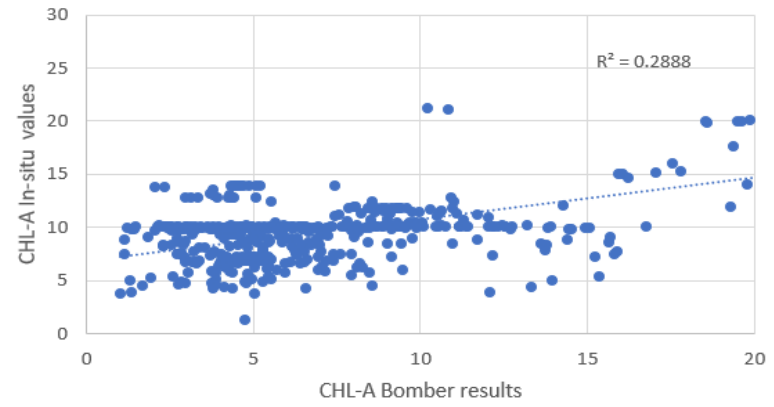

Figure 11. Comparison of in situ chl-a $(\mu \mathrm{g} / \mathrm{l})$ with estimates from BOMBER using default parameter values.

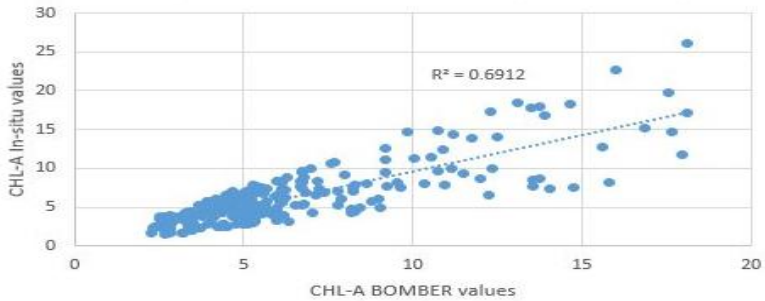

Figure 12. Comparison of in situ chl-a $(\mu \mathrm{g} / \mathrm{l})$ with estimates from BOMBER using inversed parameter values.

As expected, the correspondence between in situ chl-a and estimates from BOMBER using default parameter values is erratic, particularly for chl-a range $0-15 \mu \mathrm{g} / \mathrm{l}$ (Figure 11). The estimated chl-above $15 \mu \mathrm{g} / \mathrm{l}$ seems acceptable. Overall, the RMSE is $10.56 \mu \mathrm{g} / 1$ and $R^{2}$ is 0.2888 . Given the scatter of the values, it is not even possible to improve the estimates by adjusting them to the field data. This emphasized the need to localize the parameter values of BOMBER. The performance of BOMBER significantly improved when inversed parameter values are used instead of the defaults. R-squared increased to 0.6912. The cloud of points as shown in (Figure 12) now exhibits a more linear pattern. This suggests that inversed the spectra from in-situ field measurement would greatly increase the correlation and goodness-of-fit between the BOMBER results and the in-situ measurements. The RMSE for this case is significantly lower at $2.43 \mu \mathrm{g} / \mathrm{l}$.

\section{CONCLUSION}

The research concludes that using bio-optical model BOMBER water quality parameter maps such as chl-a, spm, and cdom of Laguna lake were produced. Furthermore, using WASI software to inverse input parameters for the BOMBER such as absorption and backscattering coefficients tool greatly improved the results of the model from a $\mathrm{R}^{2}$ of 0.2888 to a value of 0.6912 and a RSME from $10.56 \mu \mathrm{g} / \mathrm{l}$ to a value of $2.43 \mu \mathrm{g} / \mathrm{l}$. Application of this methodology could be further applied to other dates of field with overlapping over pass of Landsat 8 . Future studies could be done by applying this methodology to other types of remote sensing image like sentinel 2 .

\section{ACKNOWLEDGEMENTS}

We thank the Department of Science and Technology (DOST) for funding this research and Philippine Council for Industry, Energy and Emerging Technology Research (PCIEERD) for monitoring this project; This project was conducted under the Multi-platform and Cross-sensor Water Quality Monitoring (MCWQM) Project.

\section{REFERENCES}

Albert, A., \& Mobley, C. (2003). An analytical model for subsurface irradiance and remote sensing reflectance in deep and shallow case-2 waters. Optics Express, 11(22), 2873. https://doi.org/10.1364/OE.11.002873

Carder, K. L., Steward, R. G., Lee, Z., Mobley, C. D., \& Patch, J. S. (2008). Hyperspectral remote sensing for shallow waters I A semianalytical model. Applied Optics, 37(27), 6329. https://doi.org/10.1364/ao.37.006329

Gege, P. (2014). Computers \& Geosciences WASI-2D: A software tool for regionally optimized analysis of imaging spectrometer data from deep and shallow waters. Computers and Geosciences, 62, 208-215. https://doi.org/10.1016/j.cageo.2013.07.022

Gege, P. (2017). Radiative Transfer Theory for Inland Waters. In Bio-optical Modeling and Remote Sensing of Inland Waters. https://doi.org/10.1016/B978-0-12-804644-9.00002-1

Giardino, C., Bresciani, M., \& Braga, F. (2017). Bio-optical Modeling of Total Suspended Solids. In Bio-Optical Modelling and Remote Sensing of Inland Waters. https://doi.org/10.1016/B978-0-12-804644-9.00005-7

Giardino, C., Candiani, G., Bresciani, M., Lee, Z., Gagliano, S., \& Pepe, M. (2012). Computers \& Geosciences BOMBER: A tool for estimating water quality and bottom properties from remote sensing images. 45, 313-318. https://doi.org/10.1016/j.cageo.2011.11.022

Herrera, E. C., Nadaoka, K., Blanco, A. C., \& Hernandez, E. C. (n.d.). HYDRODYNAMIC INVESTIGATION OF A SHALLOW TROPICAL LAKE ENVIRONMENT ( LAGUNA LAKE , PHILIPPINES ) AND ASSOCIATED IMPLICATIONS FOR EUTROPHIC VULNERABILITY.

Jiménez, M., González, M., Amaro, A., \& Fernández-renau, A. (2015). Field Spectroscopy Metadata System Based on ISO. (September 2014). https://doi.org/10.3390/ijgi3031003

Kim, J., Jeung, G., \& Kim, K. (n.d.). Image Smoothing by Pseudo-2D Savitzky-Golay Filter 2 ID S-G Smoothing Filter. $120-127$.

Lee, Z., Carder, K. L., Mobley, C. D., Steward, R. G., \& Patch, J. S. (1999). Hyperspectral remote sensing for shallow waters: 2 Deriving bottom depths and water properties by optimization. $\begin{array}{lll}\text { Applied } & \text { Optics, } & 3831 .\end{array}$ https://doi.org/10.1364/ao.38.003831

Ogashawara, I., Mishra, D. R., \& Gitelson, A. A. (2017). Remote Sensing of Inland Waters. In Bio-optical Modeling and Remote Sensing of Inland Waters. https://doi.org/10.1016/b9780-12-804644-9.00001-x

Zortea, M., Salberg, A., \& Trier, O. (2012). Object-based cloud and cloud shadow detection in Landsat images for tropical forest monitoring. Proceedings of the 4th GEOBIA, 326-331.

Revised August 2019 